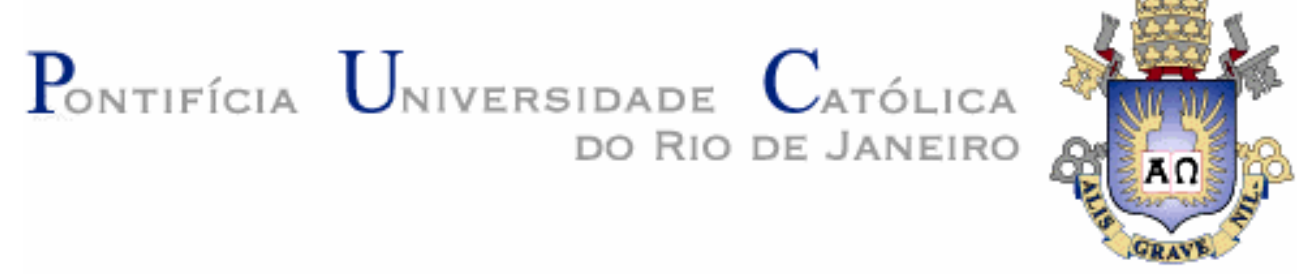

Andréa Milan dos Santos

E-learning: conhecendo alguns usuários dessa nova tecnologia

Dissertação de Mestrado

Dissertação apresentada como requisito parcial para obtenção do título de Mestre pelo Programa de PósGraduação em Psicologia da PUC-Rio.

Orientador: Prof ${ }^{a}$. Ana Maria Nicolaci-da-Costa

Rio de Janeiro Fevereiro de 2005 


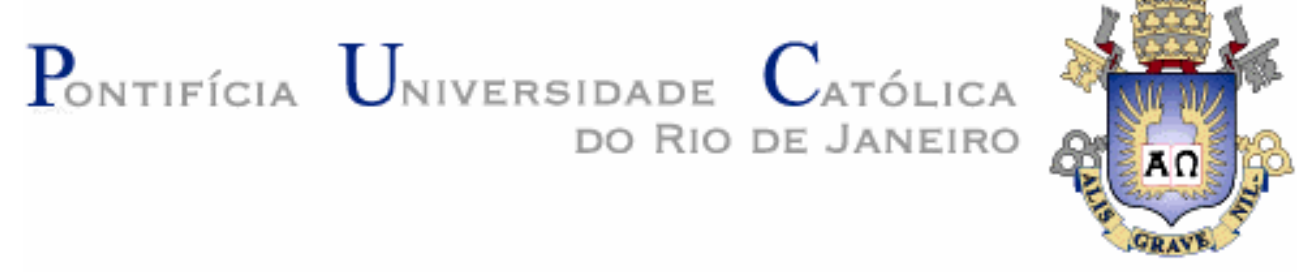

Andréa Milan dos Santos

\title{
E-learning: conhecendo alguns usuários dessa nova tecnologia
}

Dissertação apresentada como requisito parcial para obtenção do título de Mestre pelo Programa de PósGraduação em Psicologia da PUC-Rio. Aprovada pela Comissão Examinadora abaixo assinada.

\author{
Prof $^{\mathrm{a}}$. Ana Maria Nicolaci-da-Costa \\ Orientador \\ Departamento de Psicologia - PUC-Rio
}

Prof ${ }^{a}$. Monique Rose Aimée Augras Departamento de Psicologia - PUC-Rio

Prof $^{\mathrm{a}}$. Raquel Oliveira Prates Departamento de Informática - UERJ

Prof. Paulo Fernando Carneiro de Andrade Coordenador (a) Setorial do Centro de Teologia e Ciências Humanas - PUC-Rio 
Todos os direitos reservados. É proibida a reprodução total ou parcial do trabalho sem autorização da universidade, do autor e do orientador.

\section{Andréa Milan dos Santos}

Graduou-se em Administração pela UFSC (Universidade Federal de Santa Catarina) em 1999. Em 2001, concluiu o curso de Pós-Graduação em Economia da Escola da PósGraduação em Economia da FGV-RJ (Fundação Getúlio Vargas). Desde 2002, atua em empresas privadas na área de Recursos Humanos. Desenvolveu e implementou diversos cursos em e-learning.

Ficha Catalográfica

Santos, Andréa Milan dos

E-learning: conhecendo alguns usuários dessa nova tecnologia / Andréa Milan dos Santos ; orientador: Ana Maria Nicolaci-da-Costa. - Rio de Janeiro : PUC-Rio, Departamento de Psicologia, 2005.

92 f. : il. ; $30 \mathrm{~cm}$

Dissertação (mestrado) - Pontifícia Universidade Católica do Rio de Janeiro, Departamento de Psicologia

Inclui referências bibliográficas

1. Psicologia - Teses. 2. Internet. 3. E-Learning. 4. Treinamento. 5. Educação corporativa. 6. Aprendizagem organizacional. I. Nicolaci-da-Costa, Ana Maria. II. Pontifícia Universidade Católica do Rio de Janeiro. Departa mento de Psicologia. III. Título. 


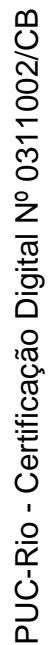

Ao meu marido Daniel, presente em todas as horas. 


\section{Agradecimentos}

À minha orientadora, Professora Ana, por ter aceitado o desafio de trabalhar com uma administradora, por ter me mostrado uma nova maneira de ver o mundo, pelo estímulo e parceria para a realização deste trabalho.

Ao meu marido Daniel que ficou ao meu lado me apoiando em todos os momentos - da ansiedade em ser aprovada para o Mestrado até o final dessa Dissertação.

À minha mãe, Maria Inês, e ao Epa, pela educação, atenção e carinho de todas as horas. Pela presença constante (mesmo à distância).

À minha sogra Flávia, pelo apoio e pelas importantes contribuições ao trabalho.

À minha avó Rita, pelas orações. À Layla e tia Elzira, por sempre me convencerem que eu sou capaz. A todos os amigos e familiares que de uma forma ou de outra me estimularam ou me ajudaram.

Às minhas colegas da PUC-Rio, Camila, Carla, Dani e Érika, pelas discussões e aprendizado nesse tempo todo. E, em especial, à Rosane, que me apresentou à Ana.

Aos meus colegas e supervisores da Shell, por todo apoio, paciência e compreensão.

Aos professores que participaram da Comissão examinadora.

A todos os professores e funcionários do Departamento pelos ensinamentos e pela ajuda.

À PUC-Rio, pelos auxílios concedidos, sem os quais este trabalho não poderia ter sido realizado. 


\section{Resumo}

Milan-dos-Santos, Andréa; Nicolaci-da-Costa, Ana Maria. E-learning: conhecendo alguns sujeitos dessa nova tecnologia. Rio de Janeiro, 2005. 92p. Dissertação de Mestrado - Departamento de Psicologia, Pontifícia Universidade Católica do Rio de Janeiro.

$\mathrm{O}$ advento da Internet resultou em grandes transformações no mundo. Nesse novo contexto, a educação à distância evoluiu bastante. A conexão de computadores em rede possibilitou a rápida troca de todo o tipo de informação e deu origem ao e-learning. As empresas logo passaram a investir na oferta de cursos virtuais para seus funcionários. Embora estes funcionários estejam de fato fazendo uso desses treinamentos virtuais no seu dia a dia, é possível perceber que esses cursos não estão tendo o sucesso esperado. Esta dissertação busca ouvir alguns desses funcionários de forma a captar suas opiniões e sentimentos em relação ao e-learning. Para tanto, foram entrevistados 20 profissionais que já realizaram cursos em e-learning. A análise das respostas revela que estas pessoas fazem cursos on-line em busca de flexibilidade de horário, adequação de agenda e agilidade. Entretanto, como principais razões para o insucesso das estratégias de e-learning, os sujeitos apontam as seguintes. (1) As empresas enfatizam a difusão de conhecimento e não estimulam a interação humana. Por conseguinte, as pessoas sentem-se sozinhas nestes cursos. (2) O conteúdo dos cursos é preparado para atender a um grande público e, por isso, não é adequado às necessidades individuais dos sujeitos. (3) Existe uma supervalorização da estética que muitas vezes coloca o conteúdo pedagógico em segundo plano. Assim, os entrevistados vêem os cursos como esteticamente agradáveis, mas carecendo de aprofundamento. Em função destes resultados sugere-se uma revisão nas estratégias de e-learning para que o seu objetivo seja alcançado de forma mais próxima à planejada.

\section{Palavras-chave}

E-learning, Internet, Educação à distância, Treinamento, Educação corporativa, Aprendizagem organizacional. 


\section{Abstract}

Milan-dos-Santos, Andréa; Nicolaci-da-Costa, Ana Maria (Advisor). Elearning: listening to some users of this new technology. Rio de Janeiro, 2005. 92p. MSc. Dissertation - Departamento de Psicologia, Pontifícia Universidade Católica do Rio de Janeiro.

The Internet has brought huge transformations in the world. In this new context, the distance learning had a broadly evolution. The connections among network computers have generated a real fast information exchange and gave birth to e-learning. Companies soon started to invest in offering virtual courses to their employees. Although these employees are, in fact, using these new training courses in their day to day, it is possible to realize that the courses are not having the expected success. This dissertation aims to listen to some of these employees in a manner that captures their opinions and feelings about elearning. For that, 20 e-learning users' workers from large companies were interviewed. The answers analysis reveals that these people take on-line courses looking for time flexibility, schedule adequateness and agility. However, as the main reasons to the lack of success of e-learning strategies, the subjects point the follow. (1) The companies emphasize knowledge diffusion and do not stimulate the human interaction. As result, people feel alone in these courses. (2) The courses' content is planned to reach a broad public and, because of this, does not fit the subjects' individual needs. (3) There is a super-aesthetic evaluation that, in many times, puts the pedagogical content in a second plan. This way, the interviewees see the courses as aesthetic, pleasant but needing a deeper approach. As a result, it is suggested a revision in these e-learning strategies in order to achieve their objectives in a more suitable way.

\section{Keywords}

E-learning, Internet, Distance learning, Training, Corporate education, Organizational learning. 


\section{Sumário}

1 Introdução 13

2 E-learning $\quad 15$

2.1. Educação à distância 15

2.1.1. Contextualização histórica da educação à distância 15

2.1.2. Definição de educação à distância 19

2.2. O e-learning 22

2.2.1. O e-learning no Brasil 25

2.2.2. Como os cursos são produzidos $\quad 27$

2.2.3. Recursos utilizados para apoiar os cursos em e-learning 28

2.2.4. Como as pessoas se inscrevem e cursam o e-learning 31

2.3. O e-learning na empresas 32

2.3.1. O aprendizado organizacional 32

2.3.2. Estratégias de treinamento com o uso de computadores em empresas 34

2.3.3. Por que o e-learning é utilizado nas empresas 36

2.3.4. Que tipo de empresa utiliza o e-learning 38

2.3.5. Quais os tipos de curso oferecidos nas empresas 41

2.3.6. E-learning: exemplo prático e definição de pesquisa 42

3 Problema de pesquisa $\quad 45$

4 O que pensam os alunos: a pesquisa de campo 46

4.1. Objetivos da pesquisa 46

4.2. Metodologia de pesquisa $\quad 47$

4.2.1. Os sujeitos $\quad 47$

4.2.2. Coleta de dados 50

4.2.3. Análise de dados 52

4.2.4. Os resultados 52

4.3. Disponibilidade e agenda 53

4.3.1. Os hábitos dos sujeitos 53

4.3.2. A busca pelo e-learning 54

4.3.3. A conexão com a Internet 57 
4.4. Os sentimentos e opiniões dos sujeitos 58

4.4.1. Impressões a respeito dos cursos $\quad 58$

4.4.2. Flexibilidade. Mobilidade 60

4.4.3. Do que eles não gostaram $\quad 61$

4.4.4. A culpa, a solidão e a inclusão 63

4.5. As pessoas aprendem mais em sala de aula 66

4.5.1. O propósito do curso $\quad 68$

$\begin{array}{ll}\text { 4.5.2. Interação humana e a flexibilidade } & 70\end{array}$

5 Alinhados no objetivo, distantes no resultado $\quad 77$

6 Considerações finais $\quad 84$

$\begin{array}{ll}7 \text { Referências bibliográficas } & 87\end{array}$

$\begin{array}{ll}8 \text { Anexo } & 91\end{array}$

8.1. Anexo1 92 


\section{Lista de tabelas}

Tabela 1: Fonte: e-learning Brasil Pesquisa - Maio de 2001 e Março de 200237

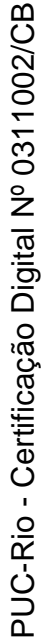




\section{Lista de figuras}

Gráfico 1: Fonte: e-learning Brasil Pesquisa - Dezembro de 2003

Gráfico 2: Fonte: e-learning Brasil Pesquisa - Dezembro de 2003

Gráfico 3: Fonte: e-learning Brasil Pesquisa - Dezembro de 2003 
"Bem-vindos ao século XXI. Somos todos imigrantes nesse novo país. Nosso mundo está mudando tão rapidamente que não conseguimos notar as diferenças, muito menos enfrentá-las. Seja chamada em espera, MTV, dinheiro digital ou lógica fuzzy, somos bombardeados todo dia por um número crescente de palavras, artefatos, idéias e acontecimentos que não entendemos. (...) Sem sair do lugar, viajamos mais longe que qualquer geração na história”.'(Rushkoff, 1999, p.8) 